\title{
Assessment is everywhere Sharing assessment information and initiatives at DePaul University
}

A CRL has pursued a number of initiatives in recent years meant to document the value of academic libraries to their users and their parent institutions, as well as to promote greater awareness across campus of the ways in which library assessment can contribute to institutional efforts to meet ever-increasing demands for accountability and demonstrated impact on student learning.

One of ACRL's flagship efforts in this area is the "Assessment in Action" (AiA) program, which is bringing together assessment teams from 300 institutions in the United States and Canada over three years to document the impact that librarians have on student learning and "to strengthen the competencies of librarians in campus leadership and data-informed advocacy." 1

\section{Benefits of AiA}

Designed in collaboration with partners from the Association for Institutional Research and the Association of Public and Land-grant Universities, AiA promotes "communities of practice" around library assessment at the local, national, and international levels. One benefit of the team-based approach taken to identifying projects to be pursued as part of AiA is the opportunity provided to team members from outside the library to become more aware of library assessment activities and what they tell us about the value of academic libraries to the institution.

Another benefit is the opportunity for librarians to become more knowledgeable about assessment activities undertaken by offices and programs across campus. After participating in AiA, librarians should not only be more skilled in the design and implementation of library assessment initiatives, but also better informed about the broader context for the assessment of student learning (and other assessment activities) on their campuses.

As Debra Gilchrist, one of the lead facilitators for the AiA program, described in her opening keynote for the 2014 Library Assessment Conference, assessment is everywhere in higher education today, and the assessment-minded librarian may take advantage of the opportunities provided by a shared assessment activity to become part of the broader assessment community on campus.

DePaul University was selected as part of the first AiA cohort with a project bringing together colleagues from the library, the Writing Center, Academic Advising, the Center for Students with Disabilities, and the Office of New Student and Family Engagement to consider the value of the library's contribution to the university's first-year experience (FYE) program, the Chicago Quarter. ${ }^{2}$

Librarians bring information literacy instruction into the broader approach to promoting academic success skills-including

Scott Walter is university librarian at DePaul University, where he also teaches in Higher Education Concentration in the School of Public Service, and an adjunct member of the faculty of the San Jose State University School of Information, email: swalte11@ depaul.edu

(c) 2014 Scott Walter 
health and wellness education and financial literacy instruction - through the Common Hour component of this program. ${ }^{3}$ Our AiA project encompassed an introduction to library spaces and services, student demonstration of information skills related to search and retrieval of materials relevant to an academic need, student reflection on the ways in which they see the library contributing to their academic success, and an assessment by members of the AiA team regarding the degree to which these assignments contributed to students developing "habits of mind" associated with success. ${ }^{4}$

\section{Office for Teaching, Learning, and Assessment}

Our experience demonstrated ways in which campus units can share responsibility for the design, implementation, and assessment of student learning in information literacy, as well as ways in which this shared approach to assessment can help to promote greater awareness of the value of information literacy instruction among colleagues.

Other AiA participants have reported similar experiences, but we believe it is worth sharing that the success of DePaul's project came within the context of an institutional commitment to the culture of assessment and the routine sharing of assessment information and initiatives.

For example, DePaul's Office for Teaching, Learning, and Assessment (TLA) coordinates a university-wide process by which every academic unit engages in an annual project to assess student learning, and provides workshops, online resources, and consultations to support that process.

As a teaching center, TLA "supports teaching and learning at DePaul by disseminating practical information about and research on teaching and learning ... . [and] providing services, resources and events focused on best practices in teaching." 5

TLA also manages the Supplemental Instruction programs that provide direct support for students in disciplines such as Economics, Biology, and Chemistry. ${ }^{6}$
Finally, TLA coordinates activities with the Academic Program Review process to ensure that annual assessment projects are incorporated into scheduled program reviews. ${ }^{7}$ The library contributes to TLA programs in a number of ways, including providing workshops on information literacy instruction as part of the Teaching and Learning Certificate Program, and providing a home for Supplemental Instruction as part of the Richardson Library Information Commons. ${ }^{8}$ As important, librarians, like TLA staff, are part of university-wide committees with responsibility for instructional improvement and for the assessment of student learning, including the Committee on Teaching, Learning, and Technology, and the Academic Program Review Committee.

\section{Collaboration of academic libraries and student affairs programs}

The culture of assessment at DePaul is also evident in the work of the Division of Student Affairs, which has collaborated with TLA and other offices to implement "an integrated assessment initiative designed to measure the day-to-day operations of the division, as well as the division's impact on student learning, engagement and involvement."

I have written before about the ways in which academic libraries and student affairs programs developed complementary foci on collaborating with academic programs and demonstrating impact on student learning across the curriculum and co-curriculum over the past two decades. ${ }^{10}$ Our shared interest in assessment that demonstrates that impact and improves professional practice is another example of this trend.

In addition to our shared work in the Chicago Quarter, the library contributes to other student affairs programs, including orientation for first-year and transfer students. More recently, student affairs programs providing direct support for student learning have been integrated into the library's Learning Commons, e.g., the Office of Multicultural Student Success "Study Jams."11 The Learning Commons launched in late 2013, and we are currently engaged with partners in 
Academic Affairs and Student Affairs to take an integrated approach to the assessment of the value of the new space and its services to student success.

\section{Executive Retention Group}

Student success is also at the center of the work of another university-wide committee that includes library representation, the Executive Retention Group (XRG). Cosponsored by the senior vice president for enrollment management and marketing and the associate vice president for academic affairs, XRG is charged with "[leading and coordinating] research, academic, and programmatic initiatives to understand and improve rates of degree completion for DePaul's diverse student population."12

The high-level endorsement needed to ensure budgetary support for the 2013 renovation that included the Learning Commons came, in part, from XRG, whose members identified the opportunity to coordinate a wide variety of decentralized student support initiatives-from research consultation to writing assistance to STEM tutoring to career counseling - in a single location as an essential component of the commitment made to our regional accrediting body to "[focus] the entire University community on student learning and success." This connection has also provided the opportunity for library data to be included as part of the institutional adoption of a new approach to the use of learning analytics. ${ }^{13}$

\section{Management Information Group}

Finally, librarians are members of DePaul's Management Information Group (MIG), which brings together individuals from offices across the university with responsibility for creating, managing, and using information to inform operational and strategic decision-making, e.g., Information Services, Institutional Research and Marketing Analytics, Human Resources, Student Affairs, Advancement, Institutional Diversity, and the Office of General Counsel. MIG provides not only a routine opportunity to share informa- tion about library assessment across a wide range of stakeholders at the institution, but also to learn of broader initiatives of which the library may wish to be a part.

Examples of the benefits of this approach have included the library's learning about the development of an institutional data warehouse that will bring library-related data to the attention of senior administrators, and the opportunity to bring assessment experts from other areas of the university into our discussion of new library assessment programs, such as the Ithaka Student Survey. ${ }^{14}$

A forthcoming study in College \& Research Libraries notes the importance of library involvement in a campus-wide assessment initiative to the successful development of a culture of assessment within the library. ${ }^{15}$ We have found that our involvement in such initiatives illustrates the trends identified in that study, but would also argue that it is critical to take the opportunities provided by any discrete initiative(s) to ensure that librarians are integrated into the committees and communication networks (formal and informal) that shape the array of assessment activities on campus, from recruitment to student learning to the use of technology in teaching to the use of campus facilities.

Collaborative efforts, such as those promoted through AiA, provide libraries with the opportunity to integrate their assessment efforts with others across campus, but we will only see sustained benefit from those efforts if we pursue those opportunities to take our place in broader assessment efforts across our institutions and to ensure that decisionmakers inside and outside of Academic Affairs are aware of the value of academic libraries to the issues of greatest concern to them.

\section{Notes}

1. "Assessment in Action: Academic Libraries and Student Success," ACRL, accessed August 8, 2014, www.ala.org/acrl/AiA.

2. "Chicago Quarter (Autumn): Discover and Explore Chicago," DePaul University Liberal Studies Program, accessed August 8, 2014, https://las.depaul.edu/academics 
/liberal-studies/first-year-program/Pages /chicago-quarter.aspx; "Chicago Quarter," DePaul University Office of New Student and Family Engagement," accessed August 8, 2014, http://studentaffairs.depaul.edu/nsfe /chicagoquarter.html.

3. Heather Jagman, Krystal Lewis, Brent Nunn, and Scott Walter, "Financial Literacy Across the Curriculum (and Beyond): Opportunities for Academic Libraries," CERL News 75, no. 5 (2014): 254-257, accessed August 9, 2014, http://crln.acrl.org/content/75/5/254. full.

4. Heather Jagman, et al., "I Felt Like Such a Freshman!': Creating Library Insiders" (poster presented at the ALA Annual Conference, Las Vegas, Nevada, June 26-July 1, 2014), accessed August 12, 2014, http:// libguides.depaul.edu/ala2014aia.

5. "About TLA," DePaul University Office for Teaching, Learning, and Assessment, accessed August 9, 2014, http://condor.depaul. edu/tla/AboutOTLA.html.

6. "Supplemental Instruction," DePaul University Office for Teaching, Learning, and Assessment, accessed August 9, 2014, http:// condor.depaul.edu/si/.

7. "Assessment," DePaul University Office for Teaching, Learning, and Assessment, accessed August 9, 2014, http://condor.depaul. edu/tla/AssessmentMain.html; "Academic Program Review," DePaul University Office of the President, accessed August 10, 2014, http://pres.depaul.edu/aprc/.

8. "Teaching and Learning Certificate Program," DePaul University Office for Teaching, Learning, and Assessment, accessed August 9, 2014, http://tlcp.depaultla.org; Richardson Library Information Commons, DePaul University Library, accessed August 9, 2014, http://libguides.depaul.edu/infocommons.

9. "Assessment," DePaul University Division of Student Affairs, accessed August 10, 2014, http://studentaffairs.depaul.edu /assessment.html.

10. Scott Walter and Michele Eodice, "Meeting the Student Learning Imperative: Supporting and Sustaining Collaboration Between Academic Libraries and Student Services Programs," Re- search Strategies 20, no. 4 (2005): 219-225.

11. "Office of Multicultural Student Success," DePaul University Division of Student Affairs, accessed August 10, 2014, http:// studentaffairs.depaul.edu/omss/; Richardson Library Learning Commons, DePaul University Library, accessed August 10, 2014, http:// libguides.depaul.edu/learningcommons.

12. "DePaul's Executive Retention Group," DePaul University Division of Enrollment Management and Marketing," accessed August 9, 2014, http://offices.depaul.edu/emm /student-retention/executive-retention -group/Pages/default.aspx.

13. "Higher Learning Commission Initiative: Foundations for Success 2013-2016," DePaul University Division of Enrollment Management and Marketing, accessed August 10, 2014, http://offices.depaul.edu/emm /student-retention/executive-retention -group/Pages/initiatives.aspx; "BlueStar," DePaul University Teaching Commons, accessed August 11, 2014, http://teachingcommons. depaul.edu/technology/bluestar.html.

14. "Ithaka S+R Local Surveys," Ithaka S+R, accessed August 10, 2014, www.sr.ithaka.org /content/ithaka-sr-local-surveys.

15. Meredith Gorran Farkas, Lisa Janicke Hinchliffe, and Amy Harris Houk, "Bridges and Barriers: Factors Influencing a Culture of Assessment in Academic Libraries," College $\mathcal{E}$ Research Libraries 76 (forthcoming), accessed August 10, 2014, http://crl.acrl.org/content/ early/2014/03/03/crl14-601.full.pdf+html. $\boldsymbol{n}$

("Internet resources," cont. from page 495)

- Linked Data: Evolving the Web into a Global Data Space. This online book published in 2011 provides a broad look at Linked Data, exploring how the technologies of Linked Data (such as RDF/XML, OWL, SKOS, and SPARQL) come together to make linked open data work. Although technical in many places, the book can serve as a good textbook for information professionals who want to understand the underlying infrastructure that makes linked open data possible. Access: http://linkeddatabook.com/. $\boldsymbol{n}$ 